\title{
Nur77, a member of the steroid receptor superfamily, antagonizes negative feedback of ACTH synthesis and secretion by glucocorticoid in pituitary corticotrope cells
}

\author{
T Okabe, R Takayanagi, M Adachi, K Imasaki and H Nawata \\ Third Department of Internal Medicine, Faculty of Medicine, Kyushu University, Fukuoka 812, Japan \\ (Requests for offprints should be addressed to T Okabe, Third Department of Internal Medicine, Faculty of Medicine, Kyushu University, Maidashi 3-1-1, \\ Higashi-ku, Fukuoka 812, Japan)
}

\begin{abstract}
Nur77 is a member of the steroid receptor superfamily and is known to be expressed in animals under stress. We studied the role of nur77 in the regulation of the hypothalamic-pituitary-adrenal (HPA) axis during the stress response using a murine pituitary corticotrope cell line, AtT-20. Corticotropin-releasing hormone (CRH), a stress mediator in the HPA axis, induced the expression of nur77 transiently in AtT-20 cells. Gel shift assay showed that nur77 bound to negative glucocorticoid responsive element (nGRE) in the promoter of the human proopiomelanocortin (POMC) gene and the formation of the nur77-nGRE complex increased after treatment of the cells with CRH. Negative GRE is known to be necessary
\end{abstract}

for the negative regulation by glucocorticoid of the POMC gene expression. In stable transformants of AtT-20 cells expressing a human homolog of nur77, NAK-1, at a high level, glucocorticoid-mediated inhibition of both POMC mRNA induction and ACTH secretion was significantly lower than that in the NAK-1-nonexpressing cells $(P<0 \cdot 001)$. These results strongly suggest that nur77 antagonizes the negative feedback effect of glucocorticoid on the synthesis and secretion of ACTH in pituitary corticotropes. This suggests that nur77 plays an important role in the pituitary gland in the biological adaptation to overcome stress.

Journal of Endocrinology (1998) 156, 169-175

\section{Introduction}

Pro-opiomelanocortin (POMC) is a precursor protein of a variety of peptide hormones including adrenocorticotropic hormone $(\mathrm{ACTH})$ which is involved in the mammalian homeostatic response to stress. In response to stress, the hypothalamic-pituitary-adrenal (HPA) axis is activated and the corticotropin-releasing hormone $(\mathrm{CRH})$ released from the hypothalamus increases both the secretion of $\mathrm{ACTH}$ and the transcription of the POMC gene in the pituitary gland. ACTH increases both the secretion of glucocorticoids from and the transcription of several steroidogenic enzymes in the adrenocortical gland, thus resulting in an increase in circulating glucocorticoids. Glucocorticoids, in turn, exert negative feedback at both the pituitary and the hypothalamic level. At the pituitary level, glucocorticoids inhibit the secretion of stored ACTH and also repress the transcription of the POMC gene (Autelitano et al. 1989, Therrien \& Drouin 1993). However, when stress continues, the blood concentration of glucocorticoids is held at an increased level, which also helps to maintain homeostasis (Meikle 1989). Therefore, in the presence of chronic stress, some antagonistic mechanism against the negative feedback effect of gluco- corticoids in the hypothalamus and/or the pituitary gland must exist.

Using transgenic mice and transfection experiments into cell lines it has been shown that the POMC 5'flanking sequence is both necessary and sufficient to confer glucocorticoid-mediated inhibition of the transcription of the POMC gene (Israel \& Cohen 1985, Tremblay et al. 1988, Hammer et al. 1990, Nakai et al. 1991, Riegel et al. 1991, Therrien \& Drouin 1993). The analysis of the POMC promoter in a pituitary corticotrope cell line, AtT-20, indicated that the in vitro binding site for glucocorticoid receptor located in the proximal region of the promoter is necessary but not, by itself, sufficient for the glucocorticoid-mediated repression of POMC (Drouin et al. 1989, 1993). This in vitro binding site for glucocorticoid receptor is called the negative glucocorticoid responsive element (nGRE) and its sequence is different from that of a consensus glucocorticoid responsive element (GRE) (Drouin et al. 1993). In addition, the molecular mechanism by which glucocorticoids inhibit the transcription of the POMC gene has yet to be elucidated.

Nur77 (Hazel et al. 1988) belongs to the steroid receptor superfamily (Evans 1988) and has a structure common to this superfamily, consisting of a highly conserved 
DNA-binding domain, a less conserved ligand-binding domain and a little conserved N-terminal domain. Nur77 is also called N10 (Ryseck et al. 1989) in mice, NGFI-B (Milbrandt 1988) or TIS1 (Kujubu et al. 1987) in rats, and NAK-1 (Nakai et al. 1990 ) or TR3 (Lee et al. 1993) in humans. Nur77 is an orphan receptor whose ligand is unknown, and has the characteristics of an immediateearly gene, the expression of which is induced transiently by several stimuli such as growth factors. The DNA sequence to which nur77 binds is called the NGFI-B responsive element (NBRE), and the consensus sequence is $5^{\prime}$-AAAGGTCA-3', consisting of two $5^{\prime}$ adenine nucleotides and the half site of the estrogen responsive element (Wilson et al. 1991). Nur77 binds to NBRE as a monomer or a heterodimer with retinoid-X receptor (Wilson et al. 1993b, Forman et al. 1995, Perlmann \& Jansson 1995). The only known target gene for nur77 is a steroid 21-hydroxylase gene (CYP21) working in the adrenocortical gland (Wilson et al. 1993a). It has been suggested that nur77 is involved in the activation-induced cell death in T-cells and also in the regulation of the HPA axis (Kastner et al. 1995), although the precise molecular mechanism involved in the function of nur77 has not yet been clarified.

In the study on a role of nur77 in the HPA axis during a stress response, we found that an NBRE-like sequence 5'-GAAGGTCA-3' exists in the promoter of the POMC gene and it overlaps with nGRE 5'-GGGAAGGTCA AAGCCCG-3', thus suggesting the possibility that the stress-induced nur77 regulates the POMC gene expression. In the present study, we demonstrate that nur77 is able to antagonize glucocorticoid-mediated inhibition of POMC gene expression in the corticotrope cell line AtT-20.

\section{Materials and Methods}

\section{Cell culture}

AtT-20 cells (ATCC CCL89), a murine corticotrope cell line which grows as small floating clusters, were cultured in RPMI 1640 (Life Technologies, Grand Island, NY, USA) containing $2 \mathrm{mM}$ L-glutamine and $5 \times 10^{-5} \mathrm{M}$ 2 -mercaptoethanol, supplemented with $10 \%$ fetal calf serum (FCS) (Hyclone, Logan, UT, USA). L-Glutamine and 2-mercaptoethanol were routinely added to RPMI 1640 in the present study. FCS in the culture media was replaced with dextran-coated charcoal (DCC)-treated FCS (namely, FCS which had been pretreated with DCC for $24 \mathrm{~h}$ ) when ovine CRH (Peptide Institute, Osaka, Japan) or dexamethasone was used.

\section{Establishment of NAK-1 stable transformants}

AtT-20 cells were washed twice with phosphate-buffered saline (PBS) and were then resuspended in $0.8 \mathrm{ml} \mathrm{FCS-}$ free RPMI $1640\left(1 \times 10^{6}\right.$ cells $\left./ 0 \cdot 8 \mathrm{ml}\right)$. One hundred microliters FCS-free RPMI 1640 containing $1.8 \mu \mathrm{g}$ NAK-1 expression vector, pCDMNAK-1 (Nakai et al. 1990), or pBluescriptSK(+) (Stratagene, Cambridge, UK) and $0 \cdot 2 \mu \mathrm{g} \mathrm{pSV} 2$ neo (Southern \& Berg 1982), and another $100 \mu \mathrm{l}$ FCS-free RPMI 1640 containing $10 \mu \mathrm{l}$ Lipofectamine (Life Technologies) were mixed gently, incubated for $15 \mathrm{~min}$ at room temperature, and added to $0.8 \mathrm{ml}$ of the cell suspension. After incubation for $5 \mathrm{~h}$ at $37^{\circ} \mathrm{C}$ in a $\mathrm{CO}_{2}$ incubator, $4 \mathrm{ml}$ RPMI 1640 with $10 \%$ FCS were added to the cells. After further incubation for $43 \mathrm{~h}$, the cells were split into 12-well plates (Falcon, Lincoln Park, NJ, USA), and cultured for one month in RPMI 1640 with $10 \%$ FCS in the presence of $0.5 \mathrm{mg} / \mathrm{ml}$ G418 (Life Technologies). To screen the clones expressing NAK-1, the whole mass of the G418-resistant cells in each well was subjected to dot blot analysis using ${ }^{32} \mathrm{P}-$ labeled NAK-1 cDNA as a probe. Finally, four different pools (namely, four different wells) of mixed clones expressing NAK-1 (NAK-1 stable transformants) and four different pools of clones not expressing NAK-1 (mock transformants) were selected.

\section{Northern blot analysis}

AtT-20 cells of non-transformants or the stable transformants were cultuted in $25-\mathrm{cm}^{2}$ suspension culture flasks. Total RNA was prepared from the cultured cells $\left(\sim 5.0 \times 10^{6}\right.$ cells $)$ by an acid guanidinium thiocyanatephenol-chloroform method (Chomczynski \& Sacchi 1987) using Isogen (Wako Pure Chemical Co., Osaka, Japan). A Northern blot analysis was performed as described previously (Okabe et al. 1995). DNA probes were prepared by PCR using AtT-20 cell-derived cDNA as the template. The sequences of sense and antisense primers were 5'-TCCATAGATGTGTGGAGCTG-3' and 5'-GTTC TTGAAGAGCGTCACCA-3' (+61 to +80 and +653 to +672 , the nucleotide positions of the sequences are represented by designating the translation start site as +1 ) respectively for the murine POMC mRNA, and 5'-

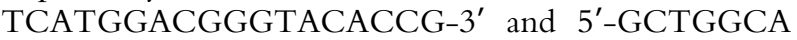
TGGAATAGCTC- $3^{\prime} \quad(+167$ to +184 and +675 to +692 ) respectively for the murine nur77 mRNA. The validity of the PCR products was confirmed by direct sequencing. For the control probe, a full-length of murine glyceraldehyde-3-phosphate dehydrogenase (GAPDH) cDNA was used. The relative intensity of each band detected by Northern blot analysis was determined using a Bio Image Analyzer BAS 2000 (Fuji Photo Film Co. Ltd, Tokyo, Japan).

\section{Electrophoretic mobility shift assay (EMSA)}

An electrophoretic mobility shift assay was performed essentially as described previously (Okabe et al. 1992). Twentyeight bp of double-stranded synthetic oligonucleotide 
corresponding to the region $73 \mathrm{bp}$ to $46 \mathrm{bp}$ upstream of the transcription start site in the human POMC gene was used as a probe. The sequence of the upper strand of the oligonucleotide is $5^{\prime}$-TGCCGGGAAGGTCAAAGT CCCGCGCCCA-3'. The nuclear extracts of AtT-20 cells were prepared according to the method of Dignam et al. (1983). Nuclear extracts $(1 \mu \mathrm{g})$ and $5 \mathrm{fmol}{ }^{32} \mathrm{P}-$ labeled probe (20 000 c.p.m.) were used for each reaction. DNA-protein complexes were analyzed on a $5 \%$ native polyacrylamide gel. Antibodies (IgG) against nur77 (Santa Cruz Biotechnology Inc., Santa Cruz, CA, USA) or glucocorticoid receptor (Santa Cruz Biotechnology Inc.) were added to the reaction mixture before adding nuclear extracts.

\section{Radioimmunoassay of ACTH}

Cells were washed twice with PBS and then resuspended in RPMI 1640 containing 2.5\% DCC-treated FCS at a densitity of $6 \times 10^{5}$ cells $/ \mathrm{ml}$. Five hundred microliters of this suspension $\left(3 \times 10^{5}\right.$ cells $)$ were dispensed into each well of 48-well plates, and incubated for $48 \mathrm{~h}$ at $37^{\circ} \mathrm{C}$ in the absence or presence of $10^{-7} \mathrm{M}$ dexamethasone. Then, the ACTH content in $5 \mu$ l of each supernatant was determined using a rat ACTH RIA kit (Peninsula Laboratories Inc., Belmont, CA, USA) according to the manufacturer's protocol.

\section{Statistical analysis}

ANOVA and the Newman-Keuls test were used for multigroup comparisons. Student's $t$-test was used for comparisons between the two groups. $P<0.05$ was considered statistically significant.

\section{Results}

\section{Induction of the nur77 expression by CRH}

The level of nur77 mRNA in CRH-treated AtT-20 cells was examined by Northern blot analysis. The expression of nur77 was weak in the resting state, but was markedly increased by $25 \mathrm{nM}$ CRH with a peak at $1 \mathrm{~h}$ after the addition of CRH. Thereafter, levels decreased gradually to those of the resting state within $24 \mathrm{~h}$. The expression of GAPDH, used as a control, did not change (Fig. 1).

\section{Binding of nur 77 to $n G R E$ in the promoter of the human POMC gene}

Using EMSA we examined whether or not nuclear extracts from AtT-20 cells contain the protein(s) which specifically binds to the nGRE sequence in the promoter region of the human POMC gene. Five shifted bands were detected and their intensity clearly increased after

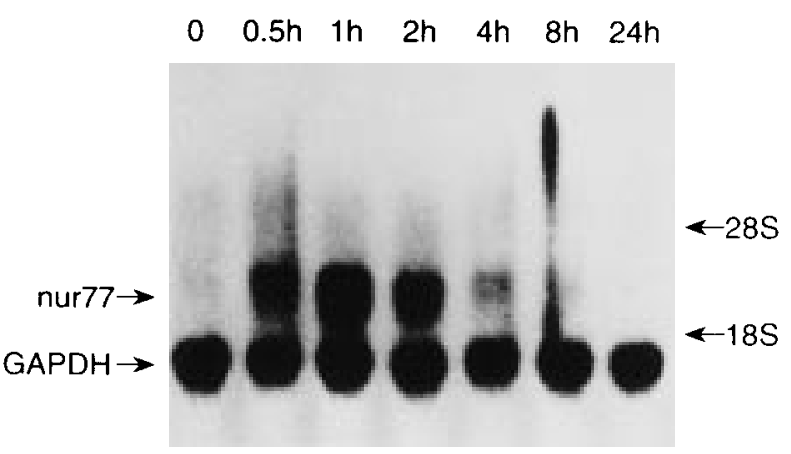

Figure 1 Induction of nur77 mRNA in cultured AtT-20 cells by CRH. AtT-20 cells $\left(5 \times 10^{6}\right.$ cells) were cultured in RPMI 1640 with $2 \cdot 5 \%$ DCC-treated FCS in $25-\mathrm{cm}^{2}$ suspension culture flasks for $24 \mathrm{~h}$ and then incubated with $25 \mathrm{nM}$ CRH. The cells were harvested at the time indicated above each lane, and the total RNA was prepared and subjected to Northern blot analysis using probes for nur77 and GAPDH simultaneously, as described in Materials and Methods. The bands corresponding to nur 77 and GAPDH mRNA are indicated by the arrows on the left, and the positions corresponding to $18 \mathrm{~S}$ and $28 \mathrm{~S}$ ribosomal RNAs on the right.

treatment of the AtT-20 cells with $25 \mathrm{nM} \mathrm{CRH}$ for $2 \mathrm{~h}$ (Fig. 2A, lanes 1 and 2). Binding to the upper four proteins of a ${ }^{32} \mathrm{P}$-labeled probe containing the human nGRE sequence was completely abolished by a 200 -fold excess of non-radioactive oligonucleotide containing intact human nGRE sequence, but not by mutated nGRE (Fig. 2A, lanes 5 and 6). Only the upper three bands, however, disappeared following the inclusion of the oligonucleotide containing the rat nGRE sequence (Fig. 2A, lane 7). These findings from the competition experiments suggest that the upper three proteins recognize an NBRE-like sequence in human and rat nGRE (see Fig. 2B). These upper three bands were extinguished by incubation of the nuclear extracts with anti-nur77 IgG (Fig. 2A, lane 4) but not with non-immune IgG (Fig. 2A, lane 3). The formation of multiple nur77-DNA complexes in size might be due to posttranslational modifications, which were identified as the cause of the heterogeneity in protein size in nur77 (Fahrner et al. 1990). On the other hand, none of the bands were abolished by incubation with antiglucocorticoid receptor antisera (data not shown). These results indicate that nur77 induced by $\mathrm{CRH}$ binds to the nGRE sequence in the POMC gene promoter in a sequence-specific manner.

Effect of nur77 expression on the glucocorticoid-mediated suppression of POMC $m R N A$ expression and $A C T H$ secretion in AtT-20 cells

To investigate further the biological effect of nur77 binding to nGRE sequence in the POMC gene promoter, we established stable transformants of AtT-20 cells expressing the human homolog of nur77, NAK-1, 
A

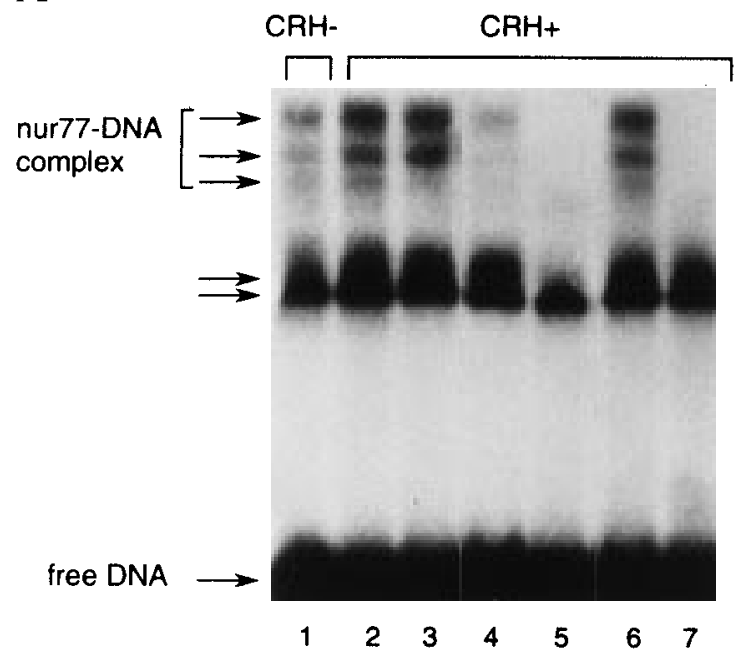

B

$$
\begin{array}{ll}
\text { human nGRE } & { }^{-69} \text { GGGAAGGTCAAAGTCCCG }^{-52} \\
\text { mutated } & \\
\text { human nGRE } & -69 \text { GGGACCGTCAAAGTCCCG } \\
\text { rat nGRE } & -72 \text { aGGAAGGTCA-CGTCCaa } \\
\end{array}
$$

consensus nur77-RE

(NBRE)

\section{AAAGGTCA}

Figure 2 Binding of nur 77 to nGRE in the promoter of the POMC gene. (A) Electrophoretic mobility shift assay (EMSA) was performed using nuclear extracts prepared from AtT-20 cells untreated (lane 1) or treated (lanes 2-7) with $25 \mathrm{nM} \mathrm{CRH}$ for $2 \mathrm{~h}$. Double-stranded oligonucleotide (28 bp) containing human nGRE was ${ }^{32} \mathrm{P}$-labeled and used as a probe, as described in Materials and Methods. Four microliters ( $4 \mu \mathrm{g}$ protein) anti-nur77 IgG (lane 4) or non-immune IgG (lane 3) were added during the incubation of nuclear extracts with a probe. An excess amount (200-fold) of non-radioactive competitors was included in the mixture: the sequences of competitors used were human nGRE (lane 5), mutated human nGRE (lane 6), and rat nGRE (lane 7). The shifted bands due to the formation of DNA-protein complexes are indicated by the arrows on the left. (B) The sequences of human nGRE, mutated human nGRE, rat nGRE, and the consensus nur77 responsive element (called NBRE) are shown. The consensus NBRE and NBRE-like sequences are underlined. The numbers show the nucleotide positions by designating the transcription start site in the POMC gene as +1 . The nucleotides of mutated human nGRE and rat nGRE that are different from those of intact human nGRE are shown by small letters, and a space is shown by a dash.

constitutively at a high level. Using the NAK-1 stable transformants, the dexamethasone-induced suppression of POMC mRNA expression and ACTH secretion was examined. The POMC mRNA level was suppressed to $70 \cdot 1 \%$ of the original level at $6 \mathrm{~h}$ after the addition of $10^{-7} \mathrm{M}$ dexamethasone and to $37 \cdot 5 \%$ at $24 \mathrm{~h}$ in mock transformants, while the POMC mRNA level decreased

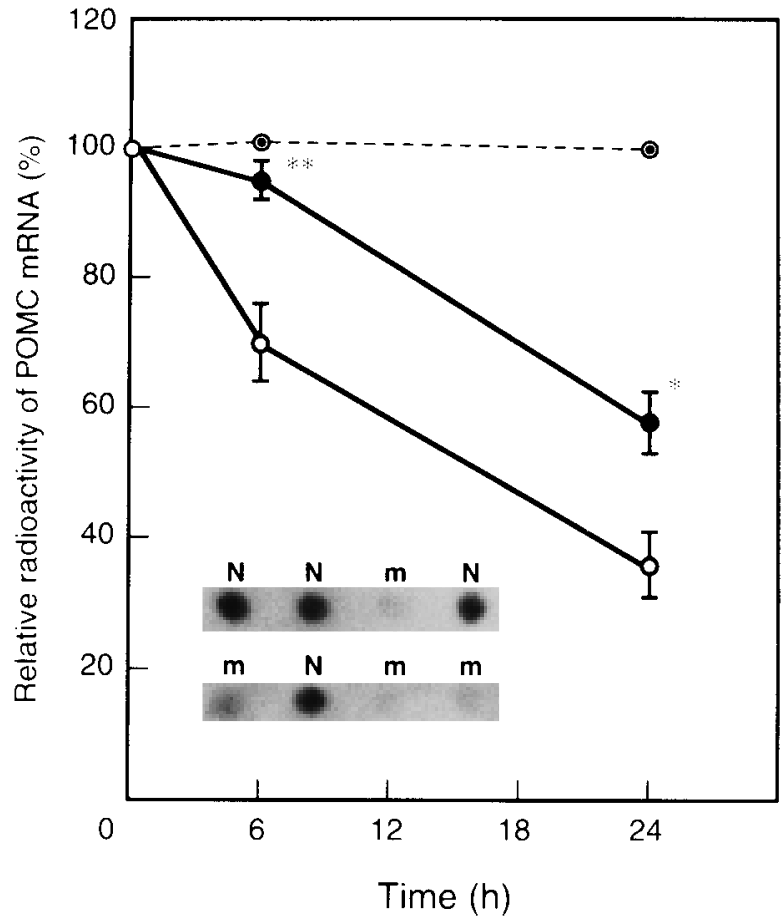

Figure 3 Effect of NAK-1 expression on the dexamethasoneinduced suppression of POMC mRNA accumulation in AtT-20 cells. NAK-1 $(\bigcirc)$ and mock $(\bigcirc)$ stable transformants $\left(5 \times 10^{6}\right.$ cells) were cultured in RPMI 1640 with $2.5 \%$ DCC-treated FCS in $25-\mathrm{cm}^{2}$ suspension culture flasks for $24 \mathrm{~h}$, and either untreated (dotted line) or treated (solid line) for $6 \mathrm{~h}$ and $24 \mathrm{~h}$ with $10^{-7} \mathrm{M}$ dexamethasone, then the total RNA was prepared and subjected to Northern blot analysis using POMC and GAPDH cDNAs as probes. Relative radioactivities of the bands detected were determined as described in Materials and Methods and the POMC mRNA level was standardized by the level of GAPDH mRNA. The POMC mRNA level before the addition of dexamethasone is given as $100 \%$ in NAK-1 and mock transformants respectively. Endogenous POMC mRNA expression in the absence of dexamethasone is similar in NAK-1 and mock transformants. The results are from four different pools of stable transformants (see Materials and Methods). Each point represents the mean \pm S.D. of four independent experiments. ${ }^{*} P<0 \cdot 01$, ${ }^{*} P<0.001$ vs mock transformants. Inset: dot blot analysis of NAK-1 and mock transformants using NAK-1 CDNA as a probe. $\mathrm{N}, \mathrm{NAK}-1$ transformant; $\mathrm{m}$, mock transformant (See Materials and Methods for details).

to only $93 \cdot 3 \%$ of the original level at $6 \mathrm{~h}$ and to $57 \cdot 6 \%$ at $24 \mathrm{~h}$ in the NAK-1 stable transformants (Fig. 3). The amount of ACTH secreted into the culture media after $48 \mathrm{~h}$ in the presence of $10^{-7} \mathrm{M}$ dexamethasone was decreased to only $86.0 \%$ of the original level in the NAK-1 stable transformants, in contrast to $59 \cdot 8 \%$ in the mock transformants (Fig. 4). In the absence of dexamethasone, the amount of both endogenous POMC mRNA expressed and ACTH secreted by the NAK-1 stable transformants was similar to that secreted by the mock transformants. The extent of the dexamethasone-induced 


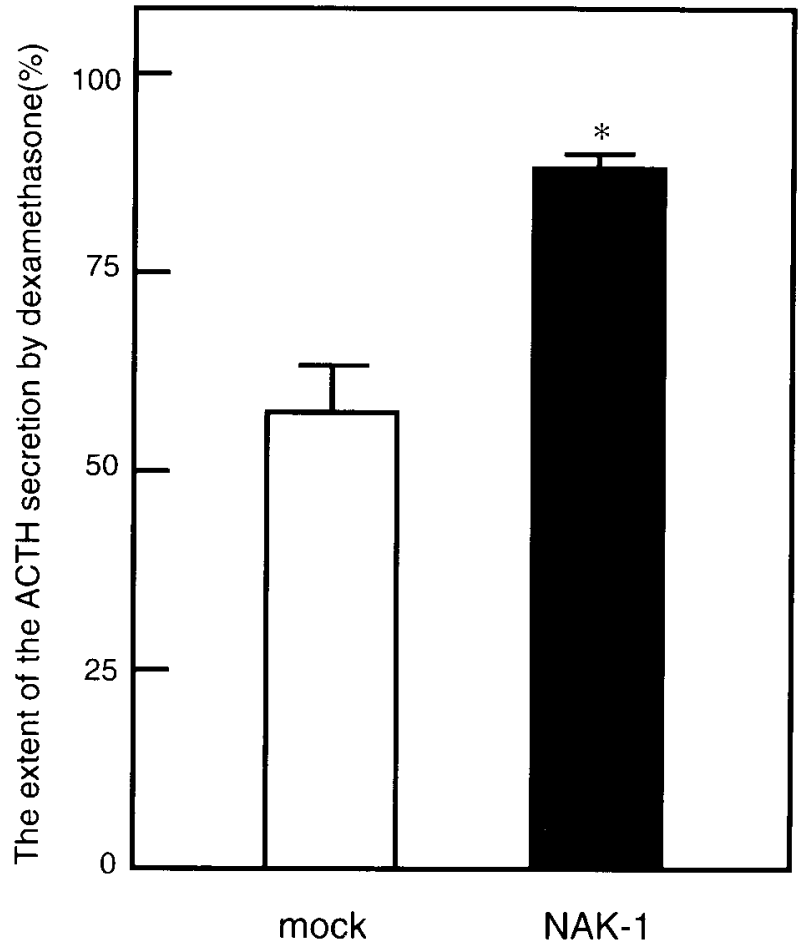

Figure 4 Effect of NAK-1 expression on the dexamethasoneinduced suppression of ACTH secretion in AtT-20 cells. NAK-1 and mock stable transformants $\left(3 \times 10^{5}\right.$ cells $)$ were cultured as described in Materials and Methods, and either untreated or treated with $10^{-7} \mathrm{M}$ dexamethasone for $48 \mathrm{~h}$, then an aliquot of each culture medium was subjected to determination of the ACTH content. ACTH concentrations in the absence of dexamethasone were given as $100 \%$ for both NAK-1 and mock transformants. Values are expressed as the mean \pm S.D. of four independent experiments with four different pools of transformants. ${ }^{\star} P<0.001$ vs mock transformants. The ACTH concentrations in the absence of dexamethasone were $896 \pm 104$ and $888 \pm 66 \mathrm{pg} / \mathrm{ml}$ (mean \pm S.D., $n=4$ ) in NAK-1 and mock transformants respectively, and were not significantly different.

suppression of the POMC mRNA expression and ACTH secretion was significantly lower in the NAK-1 stable transformants than in the mock transformants.

\section{Discussion}

We demonstrated that nur77 is induced by $\mathrm{CRH}$ in a pituitary corticotrope cell line, AtT-20, and that the expression of NAK-1, a human homolog of nur77, at a high level lowers the dexamethasone-mediated inhibition of POMC mRNA accumulation and ACTH secretion in AtT-20 cells. These observations suggest a possible mechanism of antagonizing the negative feedback effect of glucocorticoid in the HPA axis during the stress response, i.e. chronic stress induces nur77 by a mediator(s) such as $\mathrm{CRH}$ in corticotropes, and the expressed nur77 suppresses
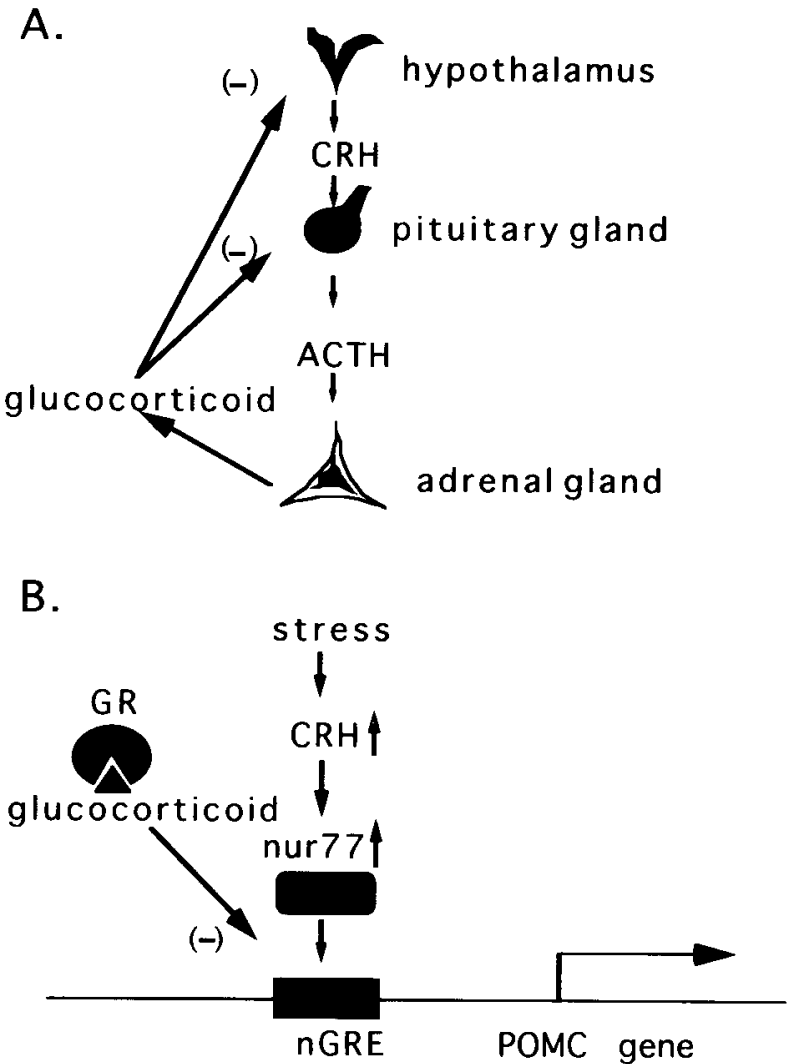

Figure 5 Schemes showing (A) the central dogma for negative feedback regulation of the hypothalamic-pituitary-adrenal (HPA) axis by glucocorticoid and (B) the hypothetical function of nur77 in the pituitary gland during the stress response. (A) $\mathrm{CRH}$ stimulates the synthesis and secretion of ACTH which results in increased circulating glucocorticoid. This, in turn, inhibits the synthesis and secretion of CRH and ACTH. (B) The expression of nur77 is induced in the pituitary gland by $\mathrm{CRH}$ released from the hypothalamus following stress stimuli. Then nur 77 binds to nGRE in the promoter of the POMC gene, thus leading to the blockade of the negative feedback by glucocorticoid, either directly or indirectly. GR, glucocorticoid receptor.

the feedback inhibition by glucocorticoid of the POMC gene expression (Fig. 5). Another mechanism in which glucocorticoid exerts less of an effect on the pituitary corticotropes during the stress response has been reported to be through CRH-mediated down-regulation in the expression of glucocorticoid receptor (Sheppard et al. 1991). There was no decrease in the expression of glucocorticoid receptor in the NAK-1 stable transformants (data not shown). Both of these mechanisms seem, therefore, to help in the maintenance of high circulating glucocorticoids during chronic stress.

Nur77 has so far been shown to be induced in the HPA axis and adrenal medulla during the stress response: nur77 is induced in the paraventricular nucleus (PVN) in the hypothalamus by the stimuli of stress (Chan et al. 1993, Parkes et al. 1993), in the adrenocortical gland by ACTH, 
and in the adrenal medulla by nicotinic stimulation mimicking sympathetic nerve stimulation (Davis \& Lau 1994). Despite many reports suggesting some involvement of nur77 in the biological adaptation to stress, it has yet to be clarified as to how the stress-induced nur77 functions. The present study demonstrates that nur77 is induced by a stress stimulus, CRH, while, in addition, nur77 exerts an antagonistic effect on the feedback inhibition by glucocorticoid.

Recently, Murphy \& Conneely (1997) showed that $\mathrm{CRH}$ treatment induced nur77 expression in AtT-20 cells, with subsequent activation of POMC gene transcription by interaction with the nGRE site of the rat POMC gene promoter. The location of the CRH- and cAMPresponsive sequences in the POMC promoter is still controversial. In our experiments, the effect of nur77 on endogenous POMC mRNA expressed and ACTH secreted by AtT-20 cells overexpressing NAK-1 was not detected. Systematic experiments need to be carried out to demonstrate that nur77 is a positive mediator of $\mathrm{CRH}$ in the transcriptional activation of the POMC gene. It is possible that nur77 might contribute little to the whole activity of endogenous POMC expression, although we cannot exclude the possibility that human NAK-1 is not capable of interacting with the mouse POMC gene promoter. Since human NAK-1 and mouse nur77 show more than $90 \%$ sequence identity at amino acid level, the latter possibility seems to be unlikely.

Crawford et al. (1995) reported an analysis of the HPA axis in nur77-deficient mice which was established by a gene-targeting technique. In these mice, the function of the HPA axis remained intact. However, an analysis of whether or not the survival rate or HPA axis is altered by exposing nur77-deficient mice to various stress stimuli may be necessary to evaluate the relevance of our above described hypothetical role of nur77. It has recently been shown that three subtypes of nur77 and nur77-like proteins constitute the nur77 family (Mangelsdorf et al. 1995, Okabe et al. 1995), and the existence of a functional redundancy among this nur77 family has been suggested (Calnan et al. 1995, Crawford et al. 1995, Kastner et al. 1995, Lee et al. 1995). Therefore, a different subtype(s) other than nur77 might compensate for the function of nur77 in the nur77-deficient mice.

The present study showed in vitro that nur77 induced by CRH in the AtT-20 cells binds to an NBRE-like sequence in the nGRE in the POMC gene promoter. No binding activity of glucocorticoid receptor to nGRE was detected by EMSA using nuclear extracts of AtT-20 cells in our study, which is consistent with the observations of other groups (Israel \& Cohen 1985, Therrien \& Drouin 1991). Purified glucocorticoid receptor is thought to be necessary for its binding to nGRE (Drouin et al. 1989, Riegel et al. 1991), surmising the existence of an inhibitor(s) of glucocorticoid receptor binding to nGRE. Negative GRE has been shown to be necessary for the glucocorticoid-mediated inhibition of the POMC gene expression (Drouin et al. 1989, 1993). Thus, our findings along with the reported observations might suggest several possible molecular mechanisms for the antagonistic effect of nur77 on the feedback inhibition by glucocorticoid (Fig. $5 B)$, including the occupation of nGRE by nur77 which may result in the hindrance of glucocorticoid receptor binding to this element. Further studies are still necessary to elucidate the precise molecular mechanism involved in the antagonistic effect of nur77.

\section{Acknowledgements}

pCDMNAK-1 was kindly provided by Professor L J DeGroot (Department of Medicine, University of Chicago). This study was supported in part by a Grantin-Aid for General Scientific Research from the Ministry of Education, Science and Culture, Japan.

\section{References}

Autelitano DJ, Lundblad JR, Blum M \& Roberts JL 1989 Hormonal regulation of POMC gene expression. Annual Review of Physiology $51715-726$.

Calnan BJ, Szychowski S, Chan FK-M, Cado D \& Winoto A 1995 A role for the orphan steroid receptor nur77 in apoptosis accompanying antigen-induced negative selection. Immunity $\mathbf{3}$ 273-282.

Chan RKW, Brown ER, Ericsson A, Kovacs KJ \& Sawchenko PE 1993 A comparison of two immediate-early genes, c-fos and NGFI-B, as markers for functional activation in stress-related neuroendocrine circuitry. Journal of Neuroscience 13 5126-5138.

Chomczynski P \& Sacchi N 1987 Single-step method of RNA isolation by acid guanidinium thiocyanate-phenol-chloroform extraction. Analytical Biochemistry 162 156-159.

Crawford PA, Sadovsky Y, Woodson K, Lee SL \& Milbrandt F 1995 Adrenocortical function and regulation of the steroid 21-hydroxylase gene in NGFI-B-deficient mice. Molecular and Cellular Biology 15 4331-4336.

Davis IJ \& Lau LF 1994 Endocrine and neurogenic regulation of the orphan nuclear receptor nur77 and NURR-1 in the adrenal glands. Molecular and Cellular Biology 14 3469-3483.

Dignam JD, LeBowitz RM \& Roeder RG 1983 Accurate transcription initiation by RNA polymerase II in a soluble extract from isolated mammalian nuclei. Nucleic Acids Research 11 1475-1489.

Drouin J, Trifiro MA, Plante RK, Nemer M, Eriksson P \& Wrange O 1989 Glucocorticoid receptor binding to a specific DNA sequence is required for hormonally-dependent repression of pro-opiomelanocortin gene transcription. Molecular and Cellular Biology 9 5305-5314.

Drouin J, Sun YN, Chamberland M, Gauthier Y, Lean AD, Nemer M \& Schmidt TJ 1993 Novel glucocorticoid receptor complex with DNA element of the hormone-repressed POMC gene. EMBO Journal 12 145-156.

Evans RM 1988 The steroid and thyroid hormone receptor superfamily. Science 240 889-895.

Fahrner TJ, Carroll SL \& Milbrandt J 1990 The NGFI-B protein, an inducible member of the thyroid/steroid receptor family, is rapidly modified posttranslationally. Molecular and Cellular Biology 10 6454-6459. 
Forman BM, Umesono K, Chen J \& Evans RM 1995 Unique response pathways are established by allosteric interactions among nuclear hormone receptors Cell 81 541-550.

Hammer GD, Fairchild-Hunters V \& Low MJ 1990 Pituitary-specific and hormonally regulated gene expression directed by the rat pro-opiomelanocortin promoter in transgenic mice. Molecular Endocrinology 4 1689-1697.

Hazel TG, Nathans D \& Lau LF 1988 A gene inducible by serum growth factors encodes a member of the steroid and thyroid hormone receptor superfamily. Proceedings of the National Academy of Sciences of the USA 85 8444-8448.

Israel A \& Cohen SN 1985 Hormonally mediated negative regulation of human pro-opiomelanocortin gene expression after transfection into mouse L cells. Molecular and Cellular Biology 5 2443-2453.

Kastner P, Mark M \& Chambon P 1995 Nonsteroidal nuclear receptors: what are genetic studies telling us about their role in real life? Cell 83 859-869.

Kujubu DA, Lim RW, Varnum BC \& Herschman HR 1987 Cloning of tetradecanoyl phorbol ester-induced 'primary response' sequences and their expression in density-arrested Swiss 3T3 cells and a TPA non-proliferative variant. Oncogene $1257-262$.

Lee HJ, Kokontis J, Wang KC \& Chang C 1993 The use of a DNA-binding domain replacement method for the detection of a potential TR 3 orphan receptor response element in the mouse mammary tumor virus long terminal repeat. Biochemical and Biophysical Research Communications 194 97-103.

Lee SL, Wesselschmidt RL, Linette GP, Kanagawa O, Russell JH \& Milbrandt J 1995 Unimpaired thymic and peripheral T cell death in mice lacking the nuclear receptor NGFI-B (nur77). Science $\mathbf{2 6 9}$ 532-535.

Mangelsdorf DJ, Thummel C, Beato M, Herrlich P, Schutz G, Umesono K, Blumberg B, Kastner P, Mark M, Chambon P \& Evans RM 1995 The nuclear receptor superfamily: the second decade. Cell 83 835-839.

Meikle AW 1989 Secretion and metabolism of the corticosteroids and adrenal function and testing. In Endocrinology, pp 1610-1632. Ed LJ De Groot. Philadelphia: WB Saunders.

Milbrandt J 1988 Nerve growth factor induces a gene homologous to the glucocorticoid receptor gene. Neuron 1 183-188.

Murphy EP \& Conneely OM 1997 Neuroendocrine regulation of the hypothalamic-pituitary-adrenal axis by the nurr1/nur77 subfamily of nuclear receptors. Molecular Endocrinology 11 39-47.

Nakai A, Kartha S, Sakurai A, Toback FG \& DeGroot LJ 1990 A human early response gene homologous to murine nur77 and rat NGFI-B, and related to the nuclear receptor superfamily. Molecular Endocrinology 4 1438-1443.

Nakai Y, Usui T, Tsukada T, Takahashi H, Fukata J, Fukushima M, Senoo K \& Imura H 1991 Molecular mechanism of glucocorticoid inhibition of human pro-opiomelanocortin gene transcription. Journal of Steroid Biochemistry and Molecular Biology 40 301-306.

Okabe T, Watanabe T \& Kudo A 1992 A pre-B- and B cell-specific DNA-binding protein, EBB-1, which binds to the promoter of the VpreB1 gene. European Journal of Immunology 22 37-43.
Okabe T, Takayanagi R, Imasaki K, Haji M, Nawata H \& Watanabe T 1995 cDNA cloning of a NGFI-B/nur77-related transcription factor from an apoptotic human $\mathrm{T}$ cell line. Journal of Immunology 154 3871-3879.

Parkes D, Rivest S, Lee S, Rivier C \& Vale W 1993 Corticotropinreleasing factor activates $\mathrm{c}-\mathrm{fos}$, NGFI-B, and corticotropin-releasing factor gene expression within the paraventricular nucleus of the rat hypothalamus. Molecular Endocrinology 7 1357-1367.

Perlmann T \& Jansson L 1995 A novel pathway for vitamin A signaling mediated by RXR heterodimerization with NGFI-B and NURR1. Genes and Development 9 769-782.

Riegel AT, Lu Y, Remenick J, Wolford RG, Berard DS \& Hager GL 1991 Pro-opiomelanocortin gene promoter elements required for constitutive and glucocorticoid-repressed transcription. Molecular Endocrinology 5 1973-1982.

Ryseck RP, Macdonald-Bravo H, Mattei MG, Ruppert S \& Bravo R 1989 Structure, mapping and expression of a growth factor inducible gene encoding a putative nuclear hormonal binding receptor. EMBO Journal 8 3327-3335.

Sheppard KE, Roberts JL \& Blum M 1991 Adrenocorticotropinreleasing factor down-regulates glucocorticoid receptor expression in mouse corticotrope tumor cells via an adenylate cyclase-dependent mechanism. Endocrinology 129 663-670.

Southern PJ \& Berg P 1982 Transformation of mammalian cells to antibiotic resistance with a bacterial gene under control of the SV40 early region promoter. Journal of Molecular Applied Genetics 1 327-341.

Therrien M \& Drouin J 1991 Pituitary pro-opiomelanocortin gene expression requires synergistic interactions of several regulatory elements. Molecular and Cellular Biology 11 3492-3503.

Therrien M \& Drouin J 1993 Molecular determinats for cell specificity and glucocorticoid repression of the pro-opiomelanocortin gene. Annals of the New York Academy of Sciences 680 663-671.

Tremblay Y, Tretjakoff I, Peterson A, Antakly T, Zhang CX \& Drouin J 1988 Pituitary-specific expression and glucocorticoid regulation of a pro-opiomelanocortin fusion gene in transgenic mice. Proceedings of the National Academy of Sciences of the USA 85 $8890-8894$.

Wilson TE, Fahrner TJ, Johnston M \& Milbrandt J 1991 Identification of the DNA binding site for NGFI-B by genetic selection in yeast. Science 252 1296-1300.

Wilson TE, Mouw AR, Weaver CA, Milbrandt J \& Parker KL 1993a The orphan nuclear receptor NGFI-B regulates expression of the gene encoding steroid 21-hydroxylase. Molecular and Cellular Biology 13 861-868.

Wilson TE, Fahrner TJ \& Milbrandt J $1993 b$ The orphan receptors NGFI-B and steroidgenic factor 1 establish monomer binding as a third paradigm of nuclear receptor-DNA interaction. Molecular and Cellular Biology 13 5794-5804.

Received 19 May 1997

Accepted 26 August 1997 